\title{
DIÁLOGOS CON LO MARGINAL WITOLD GOMBROWICZ EN LA LITERATURA ARGENTINA CONTEMPORÁNEA ${ }^{*}$
}

\author{
Ewa Kobyłecka-Piwońska \\ Universidad de Łódź \\ Departamento de Filología Hispánica
}

\begin{abstract}
Resumen. El objetivo del artículo es presentar a Witold Gombrowicz como escritor argentino. Se analiza su inclusión en el canon literario argentino echando mano de las herramientas metodológicas proporcionadas por la teoría de la "literatura mundial". Se investigan las diferentes lecturas de su obra formuladas en el marco de la crítica literaria argentina. Finalmente, se analizan las resonancias gombrowiczianas en los textos críticos y novelísticos de César Aira.
\end{abstract}

Palabras clave: Witold Gombrowicz, literatura mundial, novela argentina, crítica argentina, César Aira.

\section{DIALOGUES WITH THE MARGINS. WITOLD GOMBROWICZ IN THE CONTEMPORARY ARGENTINIAN LITERATURE}

\begin{abstract}
The aim of the article is to present Witold Gombrowicz as an Argentinian writer. His inclusion in the Argentinian literary canon is analysed by applying the methodological tools provided by the theory of "world literature". Different

\footnotetext{
* El presente articulo es fruto de una investigacion financiada por el Centro Nacional de la Ciencia (Polonia), con base en la decision DEC-2013/09/D/HS2/00563.
} 
interpretation of his literary output, proposed by the Argentinian criticism, are also investigated. Finally, the study centres on the possible links between Gombrowicz's aesthetics and Cesar Aira's literary and critical works.

Keywords: Witold Gombrowicz, world literature, Argentinian novel, Argentinian criticism, César Aira.

\section{Una literatura de exportación}

El "Gombrowicz argentino" -es decir, el autor cuya obra fue escrita exclusivamente en polaco, estudiado sin embargo como eslabón importante del canon rioplatense- parece ser el producto derivado de los imperativos de los estudios literarios actuales, que tienden a enfatizar casos de difícil filiación nacional, lingüística y genérica, concentrándose en los autores que de alguna forma representen la llamada in-betweeness: viven y/o escriben entre lenguas, culturas, países. Gombrowicz se presta a esta lectura por doble motivo, biográfico y creativo: vivió más de veinte años en la Argentina, donde se radicó en 1939 tras el estallido de la Segunda Guerra Mundial y permaneció en ella hasta 1963. Allí escribió también la mayor parte de su obra en la que no se cansó de denunciar las secuelas de cualquier identificación gregaria. La exploración crítica de la forma -nacional, lingüística, pero también individual- pesa sobre sus textos independientemente de su origen geográfico: de si fueron escritos todavía en Polonia o ya en la Argentina.

Desde las costas del Vístula, se contempla esta "usurpación" argentina de Gombrowicz con satisfacción: el autor de Ferdydurke es, sin duda, un autor central para el canon polaco y, al mismo tiempo, uno de los pocos susceptibles a la "exportación" literaria. De entre los escritores concentrados en narrar (en prosa o poesía) el martirologio de una nación injustamente maltratada, que abundaron en la literatura polaca hasta mediados del siglo XX, Gombrowicz parece ser un caso aislado del que funda su credo literario precisamente en el distanciamiento (muchas veces sarcástico o blasfe- 
mo) de la forma nacional y en la exploración sistemática del yo. Su interés por la individualidad problematizada, antecedente al advenimiento del existencialismo europeo, hace de él un autor fácilmente traducible -aunque solo en el sentido metafórico- a los códigos culturales extranjeros, indiferentes, como es comprensible, a las típicas narraciones polacas sobre la "virtud no recompensada" (Walas, 2011). Dicha satisfacción con la que se observa esta "traducción al argentino", lenguaje visto como periférico desde la perspectiva de la Europa del Este, está marcado con cierta indulgente curiosidad, propia de la manera en la cual se examinan las culturas percibidas como exóticas. En otras palabras, la mirada polaca al "Gombrowicz argentino" peca de una convicción de superioridad, porque -cotejada con la inflada gombrowiczología polaca dispuesta a revisitar por enésima vez la totalidad de su obra en busca de significados nuevos- la crítica argentina parece modesta o, en cierto aspectos, incluso reiterativa. Se le achaca la lectura en traducciones, es decir, intermediada por un código lingüístico ajeno, en el que se perderían las peculiaridades de esta literatura que trascurre precisamente en el lenguaje y, al mismo tiempo, la falta de traducciones ${ }^{1}$ lo que, a su vez, condenaría esta lectura a un irremediable fragmentarismo. Pese a estos (contradictorios) reparos, las muestras del interés argentino por el autor polaco se registran cuidadosamente, puesto que satisfacen la natural curiosidad por saber cómo se lee a este escritor polaco por excelencia en su patria adoptiva. En la introducción a su libro sobre Gombrowicz en la Argentina, su mujer confiesa primero que no esperaba encontrarse sino con el olvido de su obra, para notar luego con alivio que -una vez que llegara a Buenos Aires- sus temores resultaron totalmente injustificados; con el mismo agrado, Jerzy Jarzebski descubre allí "una generación nueva y más joven de adoradores del Maestro"; otra investigadora de la recepción argentina de Gombrowicz, Klementyna Suchanow, declara abiertamente: "Siempre me ha interesado cómo lo perciben ELLOS” (Gombrowicz, 2004: 5; Jarzębski, 2000: 234; Suchanow, 2005: 251).

1 Sobre todo de los textos que auxilian la interpretación (cartas, entrevistas, artículos de prensa). 
Es cierto, por otra parte, que la literatura nacional -si llega a leerse fuera de su contexto más inmediato, que le asegura una suerte de cómoda existencia dentro de una tradición domesticada- puede revelar capas de sentido nuevas, perceptibles solo desde este extraño "afuera". En otras palabras, en la mirada extranjera -necesariamente dotada de otra enciclopedia, otra experiencia histórica y distintas prioridades- la obra de un clásico nacional queda, por así decirlo, al desnudo, forzada a defenderse (o no) sola. Leída desde la tradición argentina, la obra gombrowicziana podría convertirse, pues, en un realización excelente de la llamada "literatura mundial", que pretende precisamente liberarse de las limitaciones impuestas por las literaturas nacionales, cuyos imperativos siempre connotan un vergonzoso provincialismo. Tan solo un Gombrowicz depurado de su polonidad -también de la más íntima materia de sus textos, la lengua polaca- podría convertirse en un clásico universal. De los modelos teóricos de la "literatura mundial" dos parecen prestarse al análisis de este particular fichaje: el de Pascale Casanova, deudor del modelo sociológico del campo literario, y el de David Damrosch, más flexible y abierto a la experiencia lectora.

\section{Sobre el concurso literario}

El funcionamiento de la, teorizada por Casanova, "República mundial de las letras" poco tiene que ver con la idea de una libre circulación de valores literarios, llamada "influencia" o "inspiración”, sino que se basa en el modelo de mercado de bienes intelectuales, en el que el monopolista impone sus jerarquías a las naciones y escritores que aspiran a la ciudadanía de ese estado imaginario. Hasta los años sesenta del siglo pasado, su capital fue París, ciudad que delimitaba "el meridano cero" de la república, artefacto que no mide el espacio, sino el tiempo:

la distancia estética se mide [...] en términos temporales: el meridiano de origen instituye el presente, es decir, en el orden de la creación literaria, la modernidad. Se puede medir 
así la distancia al centro de una obra o de un corpus de obras, con arreglo a la distancia que las separa en el tiempo de los cánones que definen, en el momento preciso de evaluación, el presente de la literatura (Casanova, 2001: 123).

Las naciones que, por motivos históricos o económicos, no consiguieron ocupar a tiempo una fuerte posición en esta república, están condenadas a una doble geografía: el lugar que ocupan sus representantes en la literatura mundial se fija según su lejanía o cercanía al meridiano cero. La admisión en la elite depende se la eficacia de las diferentes estrategias de "imponerse" (basadas en la asimilación voluntaria o, por el contrario, en la contestación de los valores admitidos en el centro), que conllevan siempre la desnacionalización de la obra: se pierde su carácter regional y autóctono; en la interpretación, se ignora el contexto geográfico e histórico local. La república literaria de Casanova es un ente algo diabólico en el que un restringido centro administra los valores "universales", sometiendo a la mayoría a una sutil violencia simbólica. Por tanto, sería ingenuo percibir la inclusión de un autor extranjero en el canon nacional como consecuencia de un inocente proceso editorial y crítico, ya que la cultura de salida y la de llegada no representan dos mundos iguales y sincrónicos:

Sólo si se capta este fenómeno a partir de la geografía específica de la literatura y de su medida estética del tiempo, es decir, a partir del trazado de las rivalidades, de las luchas y de las relaciones de fuerza que organizan el campo literario [...] se comprende de verdad cómo se «acoge», se "recibe» y se «integra» una obra extranjera (Casanova, 2001: 142).

El modelo de "literatura mundial" propuesto por Casanova converge con las intuiciones de los propios escritores, sobre todo los que habitan espacios lejanos al meridiano cero (en cambio, los que viven cerca tienden a negarlo). Gombrowicz era consciente de las fuerzas que -siendo externas a la propia literatura-intervienen en el campo literario. Escribe en el Diario: 
Me acurdo de una pequeña recepción en una casa argentina, donde un polaco, conocido mío, empezó a hablar de Polonia y por supuesto, como siempre, puso sobre el tapete a Mickiewicz y a Kosciuszko junto con el rey Sobieski y la batalla de Viena. Los extranjeros escuchaban con cortesía su ferviente discurso, tomado buena nota de que "Nietzsche y Dostoievski eran de origen polaco" y de que "tenemos dos premios Nobel de literatura". Pensé que si alguien se elogiase de esta forma a sí mismo o a su familia, demostraría una falta de tacto impresionante. Me dije que compararse de esta manera con otras naciones, haciendo hincapié en genios y héroes, méritos y logros culturales, era precisamente una torpeza terrible en la táctica propagandística, puesto que con nuestro Chopin semifrancés y Cópernico de sangre no del todo pura, no podemos competir con Italia, Francia, Alemania, Inglaterra o Rusia; de modo que nuestro punto de vista nos condena precisamente a la inferioridad (Gombrowicz, 2011: 24).

Gombrowicz no se hacía ilusiones acerca de la misma existencia del "concurso literario", ni de las reglas que lo rigen (por ejemplo, el papel consagrante del premio Nobel), ni tampoco del lugar que les tocó a Polonia y la Argentina en el mapa universal. A la larga, sin embargo, se equivocó estimando que solo jugaba en la selección polaca en este campeonato literario internacional, pues en las últimas décadas los argentinos lo vienen reclamando con insistencia.

El modelo de Casanova -por más que concuerde con las sarcásticas observaciones de Gombrowicz acerca de la transferencia intercultural de los bienes intelectuales- no se presta del todo a la descripción de su recepción tardía en la Argentina, por el mero hecho de que, en este caso, no estamos ante el desplazamiento del "capital literario" hacia el centro, sino ante su inclusión en una cultura bastante alejada del meridiano cero. Los engranajes de la República mundial trabajan impecablemente en los procesos de universalización coordinados por el centro -es cierto, por otra parte, que la argentinización de Gombrowicz acontece después de su triunfo parisino, el cual la respalda- pero no sirven para describir la inclusión de un escritor extranjero en el seno de una 
literatura considerada periférica. Es así porque dicha "argentinización" sigue un patrón contrario al descrito por la investigadora francesa: mientras que la universalización desnacionaliza (silencia las dimensiones locales de la obra), la recepción enfatiza los vínculos con la cultura que realiza la anexión. El Gombrowicz argentino será interesante en la medida en que supo ligarse "en secreto con las líneas centrales de la novela argentina contemporánea" (Piglia, 1987: 14), diagnosticar las dolencias y debilidades de esta cultura, y no como un escritor que antecede los influyentes movimientos intelectuales de la segunda mitad del XX, como estructuralismo o posestructuralismo.

Esta tensión entre centro y periferia, proveniente de la estricta jerarquización de las literaturas en el modelo de Casanova, desaparece en la propuesta de David Damrosch que se basa en la experiencia individual: la literatura mundial es aquí una circulación de textos, activada en cada acto de lectura. La estructura fija propia de la república es suplantada por la dinámica de la interpretación, puesto que cualquier cotejo de un texto con una cultura a la que tradicionalmente no pertenece ya es la manifestación de la "literatura mundial". Lo que es más, Damrosch le reserva a la cultura de acogida el derecho de incorporar el texto extranjero conforme a su propia tradición o sus propias necesidades, aunque esa libertad sea, como veremos más adelante, supeditada a una condición nada negligible. Por otra parte, parece querer garantizar a la cultura de origen ciertos derechos especiales sobre la obra: cada una fue escrita, al fin y al cabo, en el marco de alguna literatura nacional que la determinó en mayor o menor grado. El investigador norteamericano se concentra, pues, en el espacio de negociación que se abre entre ambas literaturas, insistiendo en que en este modo de lectura intercultural las posibles pérdidas (resultantes, por ejemplo, del desconocimiento del contexto de origen o de las modificaciones introducidas en la traducción) se compensan con el aumento del alcance: el texto consigue nuevos lectores. Por un lado, renuncia, es cierto, a la protección de la tradición nacional, pero, por otro, crece su potencial interpretativo. Para activar el "modo mundial de lectura” es necesario, sin embargo, estar dispuesto 
a comprometerse con el mundo ajeno (Damrosch, 2003), es decir, abrirse a lo que difiere profundamente de nuestras experiencias y percepciones más inmediatas. Damrosch es, obviamente, consciente de que este compromiso es siempre declarativo o potencial-estamos irremediablemente condicionados por la cultura de origen- pero sí exige por lo menos la disposición a no leer la obra extranjera según las pautas que organizan la literatura nacional, como si esta fuese escrita dentro de la tradición más cercana al lector. En el caso del Gombrowicz argentino, esta condición no se cumple, puesto que el contexto polaco resulta completamente prescindible: la obra se interpreta enfatizando precisamente sus lazos con la patria adoptiva del escritor, en un intento de una nacionalización al cuadrado.

\section{Crítica argentina sobre Gombrowicz}

Resulta significativo que Gombrowicz entre en la oficial historia de la literatura argentina con un notable retraso: su estancia se efectuó entre los años cuarenta y sesenta, mientras que, en la monumental Historia crítica de la literatura argentina coordinada por Noé Jitrik, le tocó el volumen relativo a la época contemporánea (la segunda mitad del XX)2 . Este desfase se explica en la introducción: el estudio no pretende registrar la mera sucesión de autores y obras, sino concentrarse selectivamente en los autores que introdujeron trasformaciones importantes dentro del canon argentino. De este modo, Gombrowicz queda integrado en él junto con otros escritores fronterizos (Copi, Wilcock y Bianciotti) bajo el rótulo "experiencias narrativas del exilio", las cuales cobraron más envergadura después del peculiar cisma cultural (dentro vs. fuera del país) impuesto por la dictadura militar. La restricción de la lengua de escritura - en cada caso, diferente al castellano- queda relegada, como obsoleta:

2 En este volumen queda incluido el artículo de Alejando Rúsovich, Gombrowicz en el relato argentino (2000: 361-377). 
En cuanto a los autores argentinos que decidieron escribir en otra lengua y el autor polaco que, escribiendo en su lengua, vivió y produjo parte de su obra en Argentina, corresponde subrayar no sólo los consabidos efectos que la relación de estos escritores con la Argentina, su país de origen o de residencia, tuvieron en su producción literaria, sino algo más radical: las crisis de las anteriores definiciones de una literatura nacional en el marco de la "globalización", de la profunda transformación económico-política de las últimas décadas del siglo. Si bien la literatura sigue siendo esencialmente un hecho de lenguaje, el edificio conceptual mismo de la lengua nacional que plantearon los románticos (siempre insuficiente para pensar la literatura hispanoamericana) exige cada vez más ser revisado y no puede ser una categoría teórica decisiva para expulsar autores que, secreta o notoriamente, tienen que ver con la literatura argentina e inciden en ella (Drucaroff, 2000: 12).

En la época global, pues, la lengua no puede ser un criterio de adscripción a tal o cual tradición literaria, sobre todo en Hispanoamérica, donde el castellano nunca pudo ser una marca distintiva de ninguna literatura nacional. Drucaroff no arriesga, obviamente, el vínculo hoy en día común entre "globalización" y "posnacionalismo": estamos, pues, ante un manual de literatura nacional cuyo objetivo es estudiarla como una entidad autónoma, regida por procesos internos más que externos. Gombrowicz -escritor que se hace argentino una vez abandonado el antiguo (lingüístico) paradigma nacionalista- resulta un eslabón importante en este desarrollo, un antecedente de la "literatura exiliada".

Efectivamente, la lectura en clave de "exilio" resulta ser la más difundida en la crítica argentina, que lee a Gombrowicz como el último en la larga serie de los intelectuales y viajeros europeos que, como escribe Juan José Saer, "repertoriaban en informes, cartas, relatos, memorias, las características de nuestro suelo, de nuestro paisaje, de nuestra sociedad, de nuestras primeras diferencias con el resto del mundo" (Saer, 2004: 23). Gombrowicz, prosigue Saer, entra en esta tradición gracias a sus viajes a Tandil, Santiago del Estero, Córdoba y Mar del Plata. Desde el punto de 
vista histórico, esta comparación con los intelectuales europeos resulta legítima -su estancia es contemporánea a los viajes de Ortega y Gasset y al exilio porteño de Roger Caillois- pero en sus travel writings, Gombrowicz nunca adopta un tono de superioridad cultural, ni siquiera le interesa una descripción objetiva de la realidad argentina (Mandolessi, 2012). Durante los años setenta y ochenta -marcados por el cultivo del exilio romántico y nostálgico- la obra gombrowicziana queda, por así decirlo, muda: sus provocativas polémicas con la patria resultan inaudibles o insignificantes dentro del campo literario desgarrado por el terrorismo del estado. La excepción a esta regla de silencio la proporciona la novela Respiración artificial de Ricardo Piglia, en cuyas páginas aparece el personaje de Tardewski (basado en Gombrowicz), pero su papel no es rememorar la patria perdida ni reflexionar sobre los cometidos de un escritor exiliado, sino precisamente dar cuenta de lo que es exterior, apócrifo o impuro dentro de la tradición nacional. El exiliado Tardewski no consolida la comunidad (ni polaca ni argentina), sino que la cuestiona, suprimiendo cualquier vínculo gregario y socavando una serie oposiciones (nosotros vs. ellos, salvajes vs. civilizados, etc.) constitutivas de una identidad nacional. Gracias a esta ambivalencia o incluso aversión hacia cualquier forma colectiva, la obra gombrowicziana anticipa la experiencia moderna del desplazamiento, para la que se ha reservado el término "migración", carente de la carga nostálgica que poseía el "exilio". El sujeto migrante vive en la franja de entre (países, culturas, lenguas), sin sentirse realmente despojado de sus raíces y definiendo su identidad individual en relación con ambos espacios que percibe como propios. Trans-Atlántico es leído, pues, como una novela "sin territorio" en la que el tradicional vínculo entre literatura y espacio (real, geográfico o imaginario) queda cuestionado: la diáspora polaca es ridiculizada, la pampa argentina supone confusión y desorden culturales. Esta lectura "espacial" de Gombrowicz - es decir, la que destaca en su obra los textos relativos al viaje, escritos desde la mirada de un forastero o "migrante" que recorre el espacio cultivando la singular ostranienie formalista- es propia de la crítica argentina: la polaca no suele atender a su clásico desde esta perspectiva. 
Otra peculiaridad de la interpretación argentina, que busca, como queda dicho, nacionalizarlo ex post, consiste en injertar su bien conocida fascinación por la juventud en el contexto político-histórico de su patria adoptiva. Sus pasajes dedicados a la exaltación de la inmadurez se leen, en la tradición polaca, como pruebas de su homosexualidad reprimida o, de forma menos directa y más metafórica, como intentos de revalorizar lo imperfecto o lo bajo por sobre lo ya formado y completo. La crítica argentina es, obviamente, consciente de ambas posibilidades interpretativas, pero además tiende a percibir este programa estético a la luz de los procesos socio-históricos acontecidos en la Argentina de los años cuarenta y cincuenta.

Su opción por los jóvenes proletarios y marginados -erótica, no social- lo instaló paradójicamente en el seno de las capas populares que estaban transformando la filosofía social argentina. ¿Acaso no era la "inconfesable y silenciosa juventud del país" con la que Gombrowicz se relacionaba en los mingitorios la misma que, a partir de 1945, vivaba a Perón en las plazas públicas? ¿Acaso la misma problemática que Gombrowicz teorizó en su diario y recreó en su narrativa -la inmadurez, lo inacabado, el desenraizmiento- no es emblemática de un momento histórico protagonizado por las masas despojadas de su terruño, forasteros en una cultura urbana ajena, cuya vida era un mero paréntesis? (Abós, 1997: 26-27).

En este pasaje, sacado de un ensayo de Álvaro Abós, se perfilan dos direcciones en las que se han constituido las lecturas argentinas de la inmadurez gombrowicziana: por un lado, el conflicto entre viejos y jóvenes se transpone en la dimensión socio-política como conflicto entre los partidarios del viejo orden y los peronistas y, por otro, se explora la obra gombrowicziana como vehículo o descriptor de una nueva cultura urbana, fundada por estos “jóvenes proletarios y marginados". La antigua metrópoli liberal del siglo XIX, que era un lugar moderno por excelencia y habitarlo era antídoto a la barbarie rural, hacia los años 30 del XX ya 
había sucumbido bajo el impacto del oleaje inmigratorio ${ }^{3}$. La sustituye una urbe multicultural y multilingüe, cuyo Gombrowicz es habitante y poeta: las noches "forradas de Retiro" descritas en su Diario y las errancias eróticas registradas en Kronos con una estoica impasibilidad 4 trazan un mapa de un Buenos Aires inmigrante, pobre y clandestino. De este modo, el autor polaco se sitúa en la estela de los escritores argentinos (como Roberto Arlt o Carlos Correas) para los cuales la narración autobiográfica, no raras veces escandalizante, se confunde con la descripción de la ciudad: calles, parques, plazas y bares de mala vida, escenarios de humillación y encuentro con el joven. "Retiro es el nombre de la vida floreciente y degradada que aventuró a Gombrowicz en sus peregrinaciones a las zonas peligrosas de la ciudad, donde la belleza nace de abajo, como el estilo" (Cangui, 2007: 82-83).

El tercer aspecto de la obra gombrowicziana que -junto con el exilio y la dinámica sociopolítica de la juventud- resulta inspirador para la crítica argentina es la cuestión de la lengua. Las peculiaridades de su estilo, que pesan tanto sobre las interpretaciones

3 Beatriz Sarlo escribe sobre esta ciudad liberal como un espacio que “imparte lecciones prácticas y debe funcionar como una buena máquina enseñante. Vivir en ciudad es etimológica y simbólicamente un acto de civilización" (Sarlo, 2007: 38).

4 Cuando apunta en Kronos sus abundantes aventuras eróticas, casi siempre juzga oportuno registrar el lugar del encuentro. Y así, por ejemplo, anota en octubre de 1950: "chico/a de la Plaza Congreso. Chico/a de 9 de Julio”. El año 1953 debuta de la siguiente manera: "Empiezo en Retiro, solo. La primera mitad del mes bajo el signo de Aldo, que no acude a rendez-vous, Libertad y Sarmiento [...]. Alrededor del 15 encuentro en Avenida Córdoba y Reconquista la amiga de Aldo y se me pasa este humor" (Gombrowicz, 2013: 150). En febrero de 1954 apunta sin ambages: "el día 5 llama Eichler, que deja el piso. El 7 (domingo) por la noche lo ocupo, voy a Retiro, encuentro a Aldo. El miércoles, en Esmeralda, a Juan Antonio. Estoy algo mejor. El sábado, Plaza Italia, Jaime. El domingo llueve. El lunes, Jorge, en Corrientes, pero no aparece ni martes ni miércoles - decepción. Martes, Antonia, Santa Fe. Jueves, Domingo, en Corrientes [...] Sábado, Osvaldo, Plaza Retiro" (Gombrowicz, 2013: 163, traducción mía). 
polacas, sus “fábulas lingüísticas" en las que el drama se construye alrededor del acto de habla (nunca transparente, inocente ni gratuito), se pierden casi por completo en la traducción. Sin embargo, la problemática de la lengua como constructora y portadora de la identidad individual se filtra en las interpretaciones argentinas de Gombrowicz desde un punto de vista diferente: su posición de un escritor con un bajo potencial lingüístico (no hablaba castellano, se negaba a hablar en francés, el polaco condenaba su obra a la no existencia) permite percibir las carencias de la literatura considerada como "culta". La conferencia "Contra los poetas" debuta de modo siguiente:

Sería más razonable de mi parte no meterme en temas drásticos porque me encuentro en desventaja. Soy un forastero totalmente desconocido, carezco de autoridad y mi castellano es un niño de pocos años que apenas sabe hablar. No puedo hacer frases potentes, ni ágiles, ni distinguidas ni finas, pero ¿quién sabe si esta dieta obligatoria no resultará buena para la salud? A veces me gustaría mandar a todos los escritores al extranjero, fuera de su propio idioma y fuera de todo ornamento y filigrana verbales para comprobar qué quedará de ellos entonces (Gombrowicz, 2009: 7).

En esta cita, reiteradas veces invocada por la crítica argentina, Gombrowicz sostiene que la exclusión del código lingüístico propio favorece la creación de una literatura nueva, depurada de la perfección formal. Como Steiner, el escritor polaco defiende que la "extraterritorialidad" -entendida como traslado de una obra hacia un terreno lingüística y culturalmente ajeno, en el que esta queda doblemente desamparada- es la fuerza que acciona la literatura moderna. Gombrowicz, que nunca cambió de lengua de escritura, no representa, es cierto, la extraterritorialidad por excelencia (característica de los escritores como Nabokov o Beckett), pero su ejemplo impulsa a Pablo Gasparini a formular el postulado de ensanchar el concepto forjado por el crítico norteamericano. Tradicionalmente aplicada al "extranjero políglota consciente de la valía de su diferencia cultural y lingüística” (Gasparini, 2010: 114), la extraterritorialidad moderna debería incluir también la 
experiencia de quienes fueron forzados a anular su idiosincrasia y asimilarse lisa y llanamente a la cultura de acogida. La tradicional imagen borgiana de la cultura argentina como "toda la cultura occidental" solo tiene en cuenta los préstamos legítimos, la desenvoltura del cosmopolita, mientras que la estética gombrowicziana -focalizada en lo que fue reprimido y negado- invita a reconocer que "tal extraterritorialidad ha sido construida también sobre la pérdida, los silencios y el regreso siempre persistente de lo aparentemente abandonado o destruido" (Gasparini, 2010: 119).

\section{El joven César Aira}

Las relaciones entre la obra de César Aira y la de Gombrowicz no han sido, hasta ahora, objeto de análisis de parte de la crítica literaria ${ }^{5}$, que prefería ocuparse del estudio de las intertextualidades entre los textos del polaco y los de Ricardo Piglia, más manifiestas, porque declaradas por mismo autor de Respiración artificial. Esta indiferencia crítica se debe, muy probablemente, a la frugalidad con la que Aira dedicaba su atención explícita a la obra gombrowicziana: cotejado con el abundante corpus pigliano sobre el polaco, sus tres cortos textos críticos ("La obra maestra secreta", "Nostalgias de un polaco en el exilio" y prólogo al libro de Juan Carlos Gómez, Gombrowicz, este hombre me causa problemas) son más que modestos, sobre todo teniendo en cuenta que Aira sí solía dedicar comentarios mucho más extensos a los autores que admiraba, como Copi o Edward Lear. Pese a esta sobriedad interpretativa, es posible establecer ciertas pautas de la lectura airiana de Gombrowicz, que me servirán más adelante como punto de partida para el cotejo de sus estéticas.

Esta lectura se orienta alrededor de dos conceptos claves: exotismo y juventud, a mbos fundamentales en la obra del escritor argentino. El texto "La obra maestra secreta" debuta del modo siguiente:

5 La única en reparar en las similitudes entre ambos fue Sandra Contreras (2002: 84-85). 
Todo el mundo reconoce que Argentina, poblada con la inmigración, periódicamente despoblada por la emigración, territorio de extraños y de ausentes, es un país que tuvo que inventarse, y la literatura que inventó para inventarse fue doblemente literaria, una literatura al cuadrado [...]. En las cimas del autoexotismo, el más argentino de los escritores argentinos terminó siendo un supuesto conde polaco que llegó a Buenos Aires por casualidad, y se quedó por accidente (Aira, 2001).

De este modo, las reflexiones sobre "el Gombrowicz argentino" quedan situadas en el contexto del exotismo, siendo ignorada por completo la cuestión del "exilio", que -como se ha visto- suele ser una trama interpretativa obligatoria. Para Aira, los posibles méritos del autor de Trans-Atlántico en la redefinición del concepto del "exilio" resultan insignificantes, y Gombrowicz solo cuenta como un usuario eficiente e innovador del procedimiento de "exotismo". Tanto la noción de "procedimiento" como la de "exotismo" se merecerían, por cierto, un comentario aparte, imposible de hacer dados los límites de extensión del presente artículo. Solo señalo que, para Aira, la categoría de "nacionalidad", estrechamente ligada con la de "exotismo", no es una condición objetiva, impuesta al escritor por el hecho de haber nacido en el seno de tal o cual nación, sino una categoría meramente estética, mediante la cual puede afirmarse la potencia inventiva de la literatura. Sobre la novela del brasileño Mario de Andrade, Macunaíma, Aira escribe:

¿No es Mario el que está manipulando un ready-made, o en todo caso un fait accompli, como es su "brasileñidad"? Creo que no [...]. Mario hizo de su obra una máquina para volverse brasileño. Es cierto que él ya era brasileño, pero eso es lo que la modernidad ha puesto en la contingencia y el azar; para hacer inteligible este dato, el brasileño debe hacer además "como si..." fuera brasileño [...]. Y ésta es la definición última con la que yo trabajo; la literatura es el medio por el que un brasileño se hace brasileño, un argentino argentino. Es lo necesario para que el Brasil se transforme en el Brasil, para que la Argentina llegue a ser la Argentina [...]. Y no hablo de llegar a ser un brasileño o un argentino de verdad, 
genuino. La autenticidad no es un valor que esté dado de antemano, esperando al individuo que lo ocupe [...]. No se trata sólo de ser argentino o brasileño, sino de inventar el dispositivo por el que valga la pena serlo, y vivir una vida siéndolo (Aira, 1993).

Para Aira, escritor neovanguardista por excelencia, los valores de "verdad" o "autenticidad" son obsoletos, lo que importa es la afirmación de la invención creativa, que precisamente echa mano del estereotipo y funda o inventa la nacionalidad manipulando los ya existentes textos de cultura. En el ciclo pampeano de Aira, los indios y los blancos juegan con su identidad estereotipada, unas veces cumpliendo con sus mandatos, y otras, negándolos de forma igualmente ostensiva. "Países como los nuestros, históricamente nuevos, ofrecen mejores condiciones para poner en marcha este mecanismo, en tanto conservan un quantun de no inventado" (Aira, 1993), escribe Aira sobre los países latinoamericanos, pero esta constatación encaja perfectamente con lo que afirmaba Gombrowicz sobre Polonia. El "quantum de lo no inventado" en la identidad nacional polaca le permitió al autor del Diario inventar otra esencia de su polonidad, "esta madurez de la inmadurez, que [...] elaboró a partir de los caracteres nacionales que es preciso inventar en el arte y el pensamiento" (Aira, 1986: 78). La interpretación de Aira -a diferencia de las que quieren ver en Gombrowicz ante todo un autor que se desvincula de su país natal- no ignora su evidente interés por la afiliación nacional la que (aunque vituperada) sigue siendo el pivote de su obra. La construcción de la identidad según Aira no consiste, evidentemente, en la deconstrucción de los mitos nacionales, ni en la afirmación del "yo" en contra de "nosotros" -todas la implicaciones ideológicas de la literatura quedan fuera de su interés- sino en una invención de la identidad nacional, admisión de una ficción de identidad, a fin de cuentas, adopción imaginaria de lo que ya se $\mathrm{es}^{6}$. Desde esta perspectiva, Peregrinaciones argentinas de Gombrowicz ofrecen el ejemplo de una literatura exótica por excelencia -el escritor emprende un viaje para contar a sus compatriotas

6 Según la expresión de Sandra Contreras (2002: 84). 
sobre un país lejano- pero también pueden leerse como un texto intermedio, que conduce al Diario argentino, en que la potencia inventiva de la ficción nacional entra en su apogeo y el escritor polaco se hace argentino. En él, "se consuma la adopción imaginaria de una nacionalidad afectada de inexistencia" (Aira, 1986: 78). Así, el polaco da un paso más que Andrade y emplea un nuevo procedimiento: inventa una identidad nacional nueva, un simulacro de la identidad que obviamente no prueba nada de verdad (las deliberaciones sobre si Gombrowicz era o no un escritor argentino son estériles), demostrando tan solo la potencia creativa de la literatura o la eficacia del nuevo procedimiento. Este no disuelve la identidad nacional -como sostienen otros interpretadores de Gombrowicz- sino que la inventa polemizando con las narraciones identitarias heredadas del siglo XIX.

Otro concepto clave para la lectura airiana del polaco es el de la "juventud", que voy a explorar a partir de la narrativa del autor argentino, o sea, lo trataré como un componente intertextual que permite cotejar ambas obras. Contrariamente a lo que ocurría con Piglia (un desarrollado aparato crítico junto con la visible ausencia de "influencias" a nivel estilístico), los textos de Aira resultan en varios aspectos cercanos a los del polaco, sobre todo a los cuentos del volumen Bacacay: los dos emplean el humor irreverente y lo grotesco que no respeta tabúes, construyen una autoficción a base de un yo que socava de forma ostensible la confianza del lector. Para Aira, la juventud -concepto fundamental del universo gombrowicziano- es, al igual que el exotismo, una categoría meramente estética; toda su dimensión metafísica, tan presente en la obra del polaco, queda, pues, fuera de su interés. En la inmadurez se condensa la vitalidad, es decir, el valor artístico que Aira defiende contra los valores connotados por la vejez: perfección, consenso, reflexión. Todos los pilares de su estética (el imperativo vanguardista de la búsqueda de lo nuevo, el procedimiento de la huida hacia adelante, el febril impulso creativo) se consideran atributos de esta edad. "El viejo y el joven: Gombrowicz lo dijo, escribe Aira, «El hombre no quiere ser Dios, el hombre quiere ser joven»" (Aira, 2004: 14). Si al autor polaco le interesaba sobre todo la dialéctica entre inmadurez y madurez, autenticidad e inautenti- 
cidad, plenitud y falta -de allí que sus textos sean profundamente contradictorios y que cuenten historias de tensiones o duelos entre el joven y el viejo- Aira apuesta únicamente por lo inmaduro, es decir, por las fábulas del Nuevo Comienzo, las historias de la catástrofe, la supervivencia y la recuperación milagrosa de la juventud.

Una de las novelas airianas de explora así entendida "inmadurez" es La serpiente, publicada en 1997. Su trama difícilmente se resume: el narrador, famoso escritor César Aira, viaja a una ciudad llamada Dinosaur City, donde piensa terminar su manual de autoayuda Cómo salir bien en las fotos. Por casualidad entra un una iglesia evangelista brasileña, en el que asiste en una ceremonia del culto al Cristo-Serpiente, tras la cual la sacerdotisa mayor lo invita a una cena, en la que participan, entre otros, dos enormes serpientes y un tal "Daniel Molina cuando fuera viejo". El narrador decide matarlo ("¿Por qué no? ¿Por qué yo nunca había tomado una decisión, nunca había actuado, nunca había corrido riesgos?", Aira, 1997: 45), lo cual hace en el baño, pero antes acaricia su barba y le recorre "un estremecimiento de excitación malsana, como si fuera la primera vez que iba a tocar a un hombre" (ibidem). Después, huye de la cena (no tanto por haber perpetrado el asesinato, sino por no querer presentar el libro escrito por la sacerdotisa), ayudado por Oscar, un chico joven. El ritmo de su huida acelera, tienen que escapar a las serpientes-perseguidoras y sobrevivir los terremotos, cataclismos frecuentes en Dinosaur City. La relación entre ambos se hace más estrecha cuando César descubre que, durante la cena, le hicieron ingerir Sodomol, una droga brasileña que inevitablemente convierte a los hombres en putos, a no ser que en una hora después de la ingestión logren acostarse con un chico joven. Los protagonistas prosiguen la huida en el ambiente de los sismos repetidos, el aluvión de serpientes que emiten balas de saliva y el pánico creciente. No logran salvarse, ya que una de las balas mata a Oscar, y entonces resulta que en realidad era un ciborg. Como si no fuera suficiente, César descubre -contemplando el cadáver de su amigo- que era el mismo de joven.

Como en casi todas las "novelitas" de Aira, la trama disparatada de La serpiente es fruto de un procedimiento narrativo de 
huida hacia adelante, que supone el ritmo acelerado de los acontecimientos, repentinos giros narrativos que desafían el orden de las relaciones causales y un desenlace rápido e inesperado. Todos estos elementos se encuentran, como queda dicho, en los cuentos de Bacacay, pero La serpiente es gombrowicziana también en otros aspectos, sobre todo en su exploración de la juventud. Dinosaur City es para "César" lo que Argentina era para Gombrowicz: un escenario de rejuvenecimiento, de retorno a la inmadurez y crecimiento de las fuerzas vitales. El siguiente fragmento de $L a$ serpiente parece una cita sacada del Diario gombrowicziano:

Cae la noche sobre Dinosaur City. Una juventud ansiosa y salvaje ocupa las calles. Vuelvo a ser joven otra vez. O por primera vez, porque no sé si fui joven antes. Debí serlo, porque soy argentino, y la Argentina es el país de la juventud (Aira, 1997: 45).

El narrador de La serpiente, como el Gombrowicz rejuvenecido en la Argentina, es inmaduro y cultiva su inmadurez, la evoca repetidas veces como su rasgo distintivo. La juventud es, además, el impulso que acelera los acontecimientos y posibilita un nuevo comienzo: en las calles de la ciudad fantástica „de pronto, me asaltaba la idea, que tan bien conozco, de que el amor era posible... La juventud en Dinosaur City exacerbaba todas mis fantasías eróticas pasadas y futuras; parecía directamente salida de ellas" (Aira, 1997: 87). El erotismo de Aira, al igual que el erotismo de Gombrowicz es liberado del dualismo de los sexos, puesto que la juventud resulta el valor en sí mismo: el típico narrador de Aira es sexualmente indeterminado, le fascinan tanto mujeres como hombres y además, como en la novela Como me hice monja, su propia identidad de género es difícil de fijar. La ambivalencia de los sexos es, pues, secundaria a la oposición Viejo-Joven o Maduro-Inmaduro, siendo la edad es el único rasgo que realmente determina a los personajes. Aira no la percibe, sin embargo, de forma tan fatídica como Gombrowicz, al que la Argentina le prolongó su juventud, pero solo para hacer más aguda la conciencia de la vejez inevitable. Para el argentino, la edad es relativa, reversible: 
los personajes se confrontan con su propio yo joven (Oscar) o con la vejez ajena ("Daniel Molina cuando fuera viejo"), el narrador se pasea por las edades de ida y vuelta: "Volver a ser joven y hacerlo todo, después de ser adulto y volver a hacerlo todo" (Aira, 1997: 57). El envejecimiento físico no es un cambio irrevocable, puesto que la tensión Viejo-Joven es meramente estética, y se traduce en el conflicto entre la convención, aburrimiento y previsibilidad por un lado, y la innovación, el azar y la improvisación por otro.

Este corto repaso de las resonancias gombrowiczianas en la literatura argentina prueba, a mi modo de ver, dos cosas. La primera es que "Gombrowicz argentino" es sustancialmente distinto a su análogo polaco: la crítica de su patria adoptiva prefiere detenerse en los aspectos y temas de su obra que, en su país de origen (y de lengua literaria), quedan insignificantes o mudos. En otras palabras, Gombrowicz en tanto precursor es inventado de forma autónoma en ambos espacios literarios. Y segundo, que el conjunto del universo gombrowicziano - su leyenda y su obra- se encuentra en la Argentina en el "campo de la intertextualidad deseada y aprobada" (Głowiński, 2000: 19), es decir, constituye un punto de referencia para una abanico de autores cuyas estéticas se perciben como distintas o, incluso, antagónicas.

\section{BIBLIOGRAFÍA}

Abós, A. (1997), El cuarteto de Buenos Aires, Buenos Aires: Colihue.

Aira, C. (1986), "Nostalgias de un polaco en el exilio", Creación, agosto-septiembre, 78.

Aira, C. (1993), "Exotismo", Boletín del Centro de Estudios de Teoría y Crítica Literaria 3, https://goo.gl/VWjxfi (acceso: 20.04.2017).

Aira, C. (1997), La serpiente, Rosario: Beatriz Viterbo.

Aira, C. (2001), "La obra maestra secreta", El País, 26 de noviembre, http://goo.gl/Fj5zcL (acceso: 7.09.2016).

Aira, C. (2004), Prólogo a Juan Carlos Gómez, Gombrowicz, este hombre me causa problemas, Buenos Aires: Interzona, 9-15.

Cangui, A. (2007), "Estampas de la decepción”, Revista la Biblioteca 7, 72-87. Casanova, P. (2001), La República mundial de las letras, Barcelona: Anagrama. Contreras, S. (2002), Las vueltas de César Aira, Rosario: Beatriz Viterbo. 
Damrosch, D. (2003), What is World Literature?, Princeton: Princeton University Press.

Drucaroff, E. (2000), “La narración gana la partida”, en: E. Drucaroff, Historia crítica de la literatura argentina, vol. 11, Buenos Aires: Emecé, 7-15.

Gasparini, P. (2010), “La extraterritorialidad del pobre”, en: N. Hochman (ed.), Pensar el afuera, Mar del Plata: Kazak Ediciones, 203-121.

Głowinski, M. (2000), „O intertekstualności”, en: M. Głowinski, Prace wybrane, vol. 5, Kraków: Universitas, 5-33.

Gombrowicz, R. (2004), Gombrowicz w Argentynie 1939-1963, Kraków: Wydawnictwo Literackie.

Gombrowicz, W. (2009), Contra los poetas, Madrid: Sequitur.

Gombrowicz, W. (2011), Diario 1954-1969, Barcelona: Seix Barral.

Gombrowicz, W. (2013), Kronos, wstęp R. Gombrowicz, posł. J. Jarzębski, Kraków: Wydawnictwo Literackie.

Jarzębski, J. (2000), „W Buenos Aires - po trzydziestu pięciu latach”, en: J. Jarzębski, Podglądanie Gombrowicza, Kraków: Wydawnictwo Literackie, 221-235.

Mandolessi, S. (2012), Una literatura abyecta. Gombrowicz en la tradición argentina, Amsterdam-New York: Rodopi.

Piglia, R. (1987), “¿Existe la novela argentina? Borges y Gombrowicz”, Espacios de crítica y producción 6: 13-15.

Rúsovich, A. (2000), "Gombrowicz en el relato argentino", en: E. Drucaroff, Historia crítica de la literatura argentina, vol. 11, Buenos Aires: Emecé, 361-377.

Saer J. J. (2004), "Perspectiva exterior. Gombrowicz en la Argentina”, en: J. J. Saer, El concepto de ficción, Barcelona: Seix Barral, 72-82.

Sarlo, B. (2007), "Buenos Aires: el exilio de Europa”, en: B. Sarlo, Escritos sobre la literatura argentina, Buenos Aires: Siglo Veintiuno Editores, 37-39.

Steiner, G. (2000), Extraterritorial, Buenos Aires: Adriana Hidalgo.

Suchanow, K. (2005), Argentyńskie przygody Gombrowicza, Kraków: Wydawnictwo Literackie.

Walas, T. (2011), „Oko innego/cudzoziemca jako możliwa perspektywa poznawcza literatury polskiej”, en: R. Nycz, W. Miodunka, T. Kunz (eds.), Polonistyka bez granic, vol. 1, Kraków: Universitas, 214-215. 